\title{
FRASEOLOGIA NOS FALARES REGIONAIS BRASILEIROS ${ }^{1}$
}

\section{PHRASEOLOGY IN BRAZILIAN REGIONAL SPEECHES}

\author{
Jacyra Andrade Mota \\ Marcela Moura Torres Paim \\ Suzana Alice Marcelino Cardoso ${ }^{2}$ \\ Universidade Federal da Bahia - UFBA
}

Resumo: Neste artigo, apresenta-se uma análise dos fraseologismos registrados nos estados de Sergipe e da Bahia, com base no que documentam os atlas linguísticos dessas regiões, respectivamente, o Atlas Lingüístico de Sergipe (ALS) e o Atlas Prévio dos Falares Baianos (APFB), e a partir do que apresentam Cardoso e Ferreira em O léxico rural. Glossário. Comentários (2000). Para tanto, apresenta-se o conjunto de fraseologias registradas, das quais se selecionam algumas para considerações específicas.

Palavras-Chave: Unidades fraseológicas; Bahia; Sergipe.

1 Artigo elaborado em 2012 que, por razões diversas, não foi publicado. Decidiu-se publicar na mesma versão original em homenagem a Professora Suzana Cardoso que iniciou o convênio referente ao Projeto CAPES-COFECUB em 2008, quando foi professora visitante da Universidade Paris 13. Atualmente, o Projeto CAPES-COFECUB 838/15 é coordenado pelos professores Salah Mejri (Universidade Paris 13) e Marcela Paim (Universidade Federal da Bahia).

2 Endereço eletrônico das autoras: jacymota@ufba.br; mmtpaim@ufba.br. 
Abstract: In this article, we present an analysis of the phraseologisms recorded in the states of Sergipe and Bahia, based on what the linguistic atlases of these regions, respectively, the Atlas Lingüistico de Sergipe (ALS) and Atlas Prévio dos Falares Baianos (APFB), and from what Cardoso and Ferreira present in The rural lexicon. Glossary. Comments (2000). For this, the set of registered phraseologies is presented, from which some are selected for specific considerations.

Keywords: Phraseological units; Bahia; Sergipe.

\section{INTRODUÇÃO}

O estudo dos falares regionais brasileiros tem suscitado o interesse de pesquisadores, de forma sistemática, pelo menos a partir do século XIX quando surgem os primeiros léxicos e glossários regionais ${ }^{3}$ a que se seguem trabalhos de cunho monográfico, iniciados com O Dialeto Caipira, em 1920, abrangendo os diversos níveis da língua, entre os quais o lexical. Tal interesse ganha corpo com trabalhos sobre áreas específicas, marcados, no seu início, pela publicação de mais duas obras que se tornaram referência, além do citado $O$ Dialeto Caipira O linguajar carioca em 1922, de autoria de Nascentes, e A língua do Nordeste, em 1934, de Marroquim. - e com a publicação de atlas regionais, o primeiro dos quais, o Atlas Prévio dos Falares Baianos (APFB), publicado em 1963, marca o início efetivo da Geolinguística brasileira.

Perseguindo a linha de interesse lexical, este artigo está voltado para a análise de aspectos do falar rural brasileiro, entendido como as diferentes manifestações da língua portuguesa no Brasil, caracterizadas por usos particulares e específicos de uma área ou de um conjunto de áreas não urbanas, geograficamente definidas e linguisticamente identificadas. Analisam-se unidades fraseológicas documentadas nos estados de Sergipe e da Bahia, com base no que documentam os atlas linguísticos dessas regiões, respectivamente, $o$ Atlas Lingüístico de Sergipe (ALS) e o Atlas Prévio dos Falares Baianos (APFB), e a partir do que apresentam Cardoso e Ferreira em O léxico rural. Glossário. Comentários (2000), a que se somam, eventualmente e de forma complemenatar, dados de outros atlas linguísticos brasileiros. Para tanto, apresenta-se o conjunto de fraseologias registradas na Bahia e em Sergipe, das quais se selecionam algumas para considerações específicas.

\footnotetext{
Como se ilustra, entre outras, com as publicações: BEAUREPAIRE-ROHAN, Visconde de. Dicionário de vocábulos brasileiros. Salvador: Progresso, 1976; GARCIA, Rodolfo. Dicionário de brasileirismos. Revista do Instituto Histórico e Geográfico Brasileiro, Rio de Janeiro, n. 76, 1912; MIRANDA, Vicente Chermont de. Glossário paraense: coleção de vocábulos peculiares à Amazônia e especialmente à Ilha de Marajó. [S. 1.]: Universidade Federal do Pará, 1968.
} 
Parte-se do princípio de que por unidade fraseológica se entende toda e qualquer frase ou expressão cristalizada, cujo sentido geral não é literal, utilizada pelos falantes em situações comunicativas específicas e cujo sentido do todo não resulta da soma do sentido das partes, como se ilustra com amarrar o facão (entrar na menopausa), mulher dama (prostituta), olho-de-boi (arco-íris), entre outras.

Considerando-se que, na literatura especializada, o conceito de fraseologismo apresenta amplo espectro, uma vez que para alguns abarca o estudo de provérbios, locuções, gírias e aforismos, para outros limita-se à consideração de expressões idiomáticas, é possível perceber que a fraseologia não possui limites claros devido à heterogeneidade, manifestada em maior ou menor amplitude, das unidades lexicais que pode abarcar e que dificilmente contém características definidoras precisas, dependendo do ponto de vista do pesquisador sobre o fenômeno linguístico analisado.

Partimos, assim, nas considerações apresentadas neste artigo, do entendimento de fraseologismo posto por Tristá (1988) que considera esse campo do estudo da linguagem como um ramo da Linguística que tem por objeto de estudo a análise de combinações de palavras as quais formam novas unidades lexicais ou têm o caráter de expressões fixas.

Considera a referida autora três traços, extremamente inter-relacionados, que caracterizam os fraseologismos, a saber: a pluriverbalidade, o sentido figurado e a estabilidade. A pluriverbalidade refere-se ao fato de todo fraseologismo estar constituído por duas ou mais palavras. $\mathrm{O}$ sentido figurado admite a metáfora como o fator semântico por excelência que atua na formação das unidades fraseológicas e, nesse sentido, a metaforização é uma das maiores forças de enriquecimento da fraseologia. Quanto à estabilidade, reconhece a autora que os elementos do fraseologismo estão relacionados entre si de forma tão estreita, que não se pode deduzir seu significado do valor semântico de seus componentes pelo fato de estes perderem seu significado primário (total ou parcialmente) para receber um novo.

Com esse entendimento, consideramos que fazem parte da fraseologia as lexias complexas, formadas por mais de uma unidade lexical - o que caracteriza o termo "pluriverbalização" (TRISTÁ, 1988), isto é, combinações fixas de significado único, estruturas sintáticas, gramaticais e semânticas, que não podem ser improvisadas e que nem sempre foram pensadas e estruturadas em nossa mente antes de as produzirmos. 


\section{OS DADOS CONSIDERADOS}

Tomou-se como base de dados para análise um conjunto de unidades fraseológicas que oferecem os atlas regionais dos estados da Bahia, o APFB (1963), e de Sergipe, o ALS (1987), partindo-se do que apresentam Cardoso e Ferreira (2000) no trabalho com o título O léxico rural. Glossário. Comentários, no qual reunem todo o léxico documentado nos dois referidos atlas. Complementarmente, faz-se referência a dados de outras áreas com o objetivo de acrescentar informação, esclarecer ou mostrar a amplitude dos usos.

Apresentam-se, a seguir, as unidades fraseológicas, ordenadas alfebeticamente e identificadas segundo o entendimento descrito no item anterior, que se constituem num conjunto de 78 ocorrências registradas nos falares rurais de Bahia e Sergipe, área que, segundo a divisão dialetal que faz Nascentes do português do Brasil (1953), se situa na região do "falar baiano".

\section{A}

AMARRADO POR DETRÁS (Adj. Avarento); AMARRAR O FACÃO (Vb. Entrar na menopausa); ARCO-CELESTE (S.m. Arco-íris); ARCO-DA-ALIANÇA (S.m. Arco-íris); ARCO-DA-VELHA (S.m. Arco-íris); ARCO-DE-BOI (S.m. Arcoíris); ARREIO DE BANDA (S.m. Sela para mulher).

\section{B}

BARRA DE NUVEM (S.f. Arco-íris); BEIÇO-D’ÁGUA (S.m. Margem de rio); BEIRA-D'ÁGUA (S.f. Margem de rio); BUNDA-CANASTRA (S.f. Cambalhota).

C

CARNEIRO-DA-ESCUMA (S.m.Ondas baixas, seguidas e espumosas); CARNEIRO-D'ÁGUA (S.m.Onda); CARNEIRO-DE-MAR (S.m.Onda); CASCODE-CUIA (Adj. Tipo de mestiço); CIGARRO DE FUMO (S.m. Cigarro feito à mão); CIGARRO DE LEGUME (S.m. Cigarro feito à mão); CIGARRO DE PALHA (S.m. Cigarro feito à mão); CAIR O FACÃO (Vb. Entrar na menopausa): COURO-DE-ONÇA (Adj. Branco e preto); COURO-DE-RAPOSA (Adj. Branco e preto); CURTO-DA-VISTA (Adj. Pessoa que enxerga pouco).

D

DENTE QUEIRO (S.m. Dente do siso); DONA-DO-CORPO (S.f. Útero); DORD'OLHOS (S.m. Conjuntivite).

E

ESCUMA-DE-SAPO (S.f.Ondas baixas, seguidas e espumosas); ESTAR DE AFONSO (Vb. Estar menstruada); ESTAR DE QUINOGIA (Vb. Estar 
menstruada); ESTOU-FRACO (S.f. V. Galinha-d'angola); ESTRELA CORREDEIRA (S.f. Estrela cadente).

$\mathbf{F}$

FAIXA-BRANCA (S.f. Espécie de porco que cresce pouco e engorda muito); FAZEDOR DE MOCAMBA (S.m. Feiticeiro); FLOR-D'ÁGUA (S.f. Tona d'água) FORMIGA-DE-ROÇA (Adj.Tipo de mestiço, ruivo).

G

GALINHA-D'ANGOLA (S.f. Ave da família dos galináceos, originária da África); GANHADOR DE ENXADA (S.m. Trabalhador de enxada em roça alheia); GANHADOR DE PATACA (S.m. Trabalhador de enxada em roça alheia); GUARDA-LORO (S.m. Peça de arreio, correia dupla afivelada à sela ou selim para sustentar o estribo); GUARDA-SEIO (S.f. Sutiã).

L

LUME-D'ÁGUA (S.m. Tona d'água).

M

MADRE-PÉROLA (S.f. Pérola); MÃE-D’ÁGUA (S.f. Tona d'água); MÃE-DOCORPO (S.f. Útero); MÃO-APERTADA (Adj. Avarento); MARIA-CAMBONA (S.f. Cambalhota); MARIA-CAMBOTA (S.f. Cambalhota); MARIA-CANASTRA (S.f. Cambalhota); MARIA-TUBI (S.f. Cambalhota); MORTO-A-FOME (Adj. Avarento); MULHER-DAMA (S.f. Meretriz); MULHER-SOLTEIRA (S.f. Meretriz).

$\mathbf{N}$

NEVE-D'ÁGUA (S.f. Tona d'água).

$\mathrm{O}$

OLHO-D’ÁGUA (S.m. Tona d'água); OLHO-DE-BOI (S.m. Arco-íris; Olho esbugalhado); OSSINHO-DA-FONTE (S.m. Clavícula); OSSO-DA-FOME (S.m. Clavícula); OVO-DE-PERU (S.m. Sarda).

$\mathbf{P}$

PÃO-DURO (Adj. Avarento); PAPO-DE-PERU (S.m. Sarda); PAU-DEGALINHA (S.m. haste de madeira que se atravessa no ombro ou no pescoço, em cuja extremidade se penduram galinhas para serem transportadas); PINTA DE NEGRO (S.f. Sinal, pequena mancha escura na pele); POTE-QUEBRADO (S.m. Menstruação); PULO-MORTAL (S.m. Cambalhota).

Q

QUEBRAR O FACÃO (Vb. Entrar na menopausa). 


\section{$\mathbf{R}$}

REPARTIÇÃO-DE-MÊS (S.f. Menstruação).

S

SALTO-MORTAL (S.m. Cambalhota); SELA-DE-BANDA (S.f. Sela para mulher); SENHORA-DO-CORPO (S.f. Útero); SETE-CORES (S.m. Arco-íris); SUSTENTA-SEIO (S.m. Sutiã).

\section{T}

TIRAR O FACÃO (Vb. Entrar na menopausa); TRABALHADOR ALUGADO (S.m. Trabalhador de enxada em roça alheia); TRABALHADOR DE ALUGUEL (S.m. Trabalhador de enxada em roça alheia); TURVO DA(S) VISTA(S) (Adj. Pessoa que enxerga pouco).

$\mathbf{U}$

UNHA-DE-FOME (Adj. Avarento).

V

VARRE-RUA (S.f. Meretriz); VEIA-D'ÁGUA (S.f. Tona d'água); VISTA CURTA (S.m. Miopia).

\section{1 Estrutura morfológica}

Considerando a forma como se estruturam, identificam-se os seguintes tipos, dos quais se apresenta descrição seguida de exemplo ilustrativo e do número de ocorrências no total do corpus.

a) SUBSTANTIVO + PREPOSIÇÃO + SUBSTANTIVO (35 ocorrências) - Ex.: arco-de-boi

b) SUBSTANTIVO + PREPOSIÇÃO + ARTIGO + SUBSTANTIVO (8 ocorrências) - Ex.: dona-do-corpo

c) SUBSTANTIVO + SUBSTANTIVO (7 ocorrências) - Ex.: mulherdama

d) SUBSTANTIVO + ADJETIVO (12 ocorrências) - Ex.: arco-celeste

e) NUMERAL + SUBSTANTIVO (uma ocorrência) - Ex.: sete-cores

f) ADJETIVO + PREPOSIÇÃO + ARTIGO + SUBSTANTIVO (duas ocorrências) - Ex.: curto-da-vista

g) VERBO + SUBSTANTIVO (4 ocorrências) - Ex.: porta-seio

h) VERBO + ADJETIVO (uma ocorrência) - Ex.: estou-fraco

i) VERBO + ARTIGO + SUBSTANTIVO (4 ocorrências) - Ex.: quebrar o facão

j) VERBO + PREPOSIÇÃO + SUBSTANTIVO (3 ocorrências) - Ex.: estar de afonso 
k) VERBO + PREPOSIÇÃO + ADVÉRBIO (uma ocorrência) - Ex.: amarrado por detrás.

\section{COMENTÁRIOS A ALGUMAS UNIDADES FRASEOLÓGICAS}

O conjunto de unidades fraseológicas registradas nessa área brasileira apresenta interesse linguístico-cultural uma vez que possibilita elementos para interpretação da relação homem-meio em que vive, não só numa perspectiva sincrônica, mas também diacrônica. Explorando tais aspectos, destacam-se algumas das fraseologias registradas para, sobre elas, aprofundar-se a maneira como se dá o seu uso. Serão considerados os seguintes itens semântico-lexicais: arco-íris, prostituta e entrar na menopausa.

\subsection{Expressões para arco-íris}

Na Bahia e em Sergipe, como se registra nos atlas linguísticos desses estados, para denominar o fenômeno identificado como "arco-íris" ocorreram as seguintes estruturas fraseológicas: arco-celeste, arco-da-aliança, arco-da-velha, arco-de-velho, arco-de-boi, arco-íris, barra de nuvem, olho-de-boi, sete-cores. A esse rol podem-se agregar denominações, algumas coincidentes com as já citadas, ocorrentes nos estados do Amazonas, Ceará, Paraíba, Mato Grosso do Sul, Minas Gerais e Paraná, conforme se registra nos seus respectivos atlas linguísticos, todos eles publicados, à exceção do referente ao Estado do Amazonas que se constitui em tese de doutoramento. Desprezam-se, porém, os casos de ocorrências únicas que podem ser explicados como traço idioletal. Assim, para denominar o fenômeno identificado por "arco íris", ocorrem, nesse conjunto de oito estados brasileiros, as seguintes denominações, das quais uma - arco-íris - é comum a todos esses espaços:

\begin{tabular}{|l|l|}
\hline \multicolumn{1}{|c|}{ DENOMINAÇÃO } & \multicolumn{1}{c|}{ LOCALIDADE } \\
\hline Aliança-do-céu & Mato Grosso do Sul \\
\hline Arca-de-noé & Mato Grosso do Sul \\
\hline Arco-celeste & Bahia, Sergipe e Ceará \\
\hline Arco-da-aliança & Bahia, Minas Gerais, Paraná e Ceará \\
\hline Arco da nova aliança & Paraná \\
\hline Arco-da-velha & $\begin{array}{l}\text { Bahia, Sergipe, Minas Gerais, Paraná e } \\
\text { Ceará }\end{array}$ \\
\hline Arco-de-boi & Bahia, Sergipe e Ceará \\
\hline Arco-de-velho & $\begin{array}{l}\text { Mato Grosso do Sul, Bahia, Sergipe e } \\
\text { Paraná }\end{array}$ \\
\hline
\end{tabular}




\begin{tabular}{|l|l|}
\hline Arco-do-sol & Minas Gerais \\
\hline Arco-íris & $\begin{array}{l}\text { Amazonas, Paraíba, Bahia, Sergipe, } \\
\text { Minas Gerais, Mato Grosso do Sul, } \\
\text { Paraná e Ceará }\end{array}$ \\
\hline Barra de chuva & Ceará \\
\hline Barra de nuvem & Bahia \\
\hline Cu-de-boi & Paraíba \\
\hline Escama-de-peixe & Ceará \\
\hline Mãe-d'água & Minas Gerais \\
\hline Olho-de-boi & $\begin{array}{l}\text { Bahia, Minas Gerais, Paraíba, Sergipe } \\
\text { e Ceará }\end{array}$ \\
\hline Papa peixe & Mato Grosso do Sul \\
\hline Rabo-de-galo & Minas Gerais e Mato Grosso do Sul \\
\hline Rabo-de-pavão & Minas Gerais \\
\hline Sete-cores & Bahia \\
\hline Sub-douradas & Paraíba \\
\hline
\end{tabular}

Como se observa do rol de denominações apresentado, do ponto de vista da sua composição registram-se diferentes tipos de estruturas que podem ser, assim, descritas:
(a) substantivo+preposição+substantivo (olho-de-boi)
(b) substantivo+preposição+artigo+substantivo (arco-da-aliança)
(c) substantivo+preposição+artigo+adjetivo+ substantivo (arco-da-nova- aliança)
(d) substantivo+adjetivo (arco-celste)
(e) verbo+substantivo (papa-peixe)
(f) numeral+substantivo (sete-cores)

Para estas considerações, porém, interessam particularmente os aspectos motivacionais e semânticos de que se reveste esse conjunto de denominações.

O amplo rol de designações para arco-íris, no Brasil, exibe um vasto espectro de motivações que deram origem às diferentes formas. Do ponto de vista dos processos de criação, registram-se grupos diferenciados segundo a natureza da formação que refletem. Assim, identificam-se (i) designações pautadas na motivação "arco", (ii) designações com outras motivações do principal elemento componente, (iii) formas que atestam casos de zoomorfismo e (iv) formas que exemplificam a presença de casos de antropomorfismo.

A motivação "arco" está fartamente presente nesse conjunto de nomes, tratando-se de denominação altamente transparente que, servindo-se da forma como o fenômeno é visualizado, atribui-lhe características que se expressam no 
elemento tomado para comparação. Essa qualificação do elemento principal segue diferentes caminhos, como se passa a examinar:

(i) Denominações que trazem referência à abóbada celeste ou a elementos nela existentes (arco celeste, arco-do-sol)

(ii) Denominações que tomam como elemento de comparação um animal, aspecto que, também, vai se inserir nos casos de zoomorfismo (arco de boi)

(iii) Denominações que evocam conceito religioso-cristão (arco da aliança)

Um segundo grupo é constituído por designações com outras motivações do elemento principal que, observadas, permitem reconhecer-se que o processo de metaforização se orienta por motivações distintas, a saber:

(i) Associa-se o fenômeno à cauda de animais, por exemplo, galo ou pavão (rabo de galo)

(ii) Toma-se a denominação barra que, pelo menos na Bahia e em Sergipe, designa, também, a "aurora", o "romper do dia" (barra de nuvem)

Casos de zoomorfismo se exemplificam com as ocorrências rabo de galo, rabo de pavão, olho de boi e cu de boi em que os mecanismos de relação ora são mais evidentes, como em rabo de galo e em rabo de pavão, ora se apresentam menos nítidos, como em olho de boi e cu de boi. Para os dois primeiros casos, parece evidente a associação: o tipo de cauda que possuem esses animais, menos densa e menos colorida no galo e mais densa e com maior efusão de cores no pavão, parece explicar a relação. A relação que se estabelece com o boi não se afigura, porém, muito clara. A denominação olho de boi não se restringe, porém, ao Brasil uma vez que está documentada na França - oeuf de boeuf segundo os dados do Atlas Linguarum Europae - ALE (Carta I.9). A propósito do zoormorfismo nos nomes para arco-íris, Alinei (1983, p.30) se refere às denominações com motivação em animais dizendo que "thus reflect an ancient totemic vision of reality".

Os casos de antropomorfismo se vêem representados em denominações como arco-íris, arco da velha, arco-do-velho, arco-da-aliança, arco-da-nova-aliança. O ALE, na Carta I.9, reconhece um "anthopomorphisme païen" e um "anthopomorphisme crétien et islamique". Interpretadas essas denominações à luz do que se vê no ALE, a denominação arco-íris figura entre os casos de antropomorfismo pagão uma vez que toma a divindade Íris, mensageira alada 
dos deuses, que se recobria com um xale de sete cores, identificado como o próprio arco-íris. De outra parte, arco-da-aliança pode figurar entre os casos de antropomorfismo cristão.

Postas estas considerações gerais sobre as denominações para arco-íris no Brasil, tomam-se, para uma ampliação dos comentários, as expressões fraseológicas arco da velha, arco-do-velho, arco-da-aliança, arco-da-nova-aliança.

Para todas elas a motivação do elemento principal é a palavra arco, que evoca a forma que assume o fenômeno na abóbada celeste, a qual vem qualificada por da velha, do velho, da aliança, da nova aliança. Uma questão se põe a seguir: como qualificar, quanto à natureza da motivação, essas denominações e como enquadrá-las em um tipo de antropomorfismo - pagão ou cristão.

A denominação arco da velha está presente no ALE e vem classificada entre os casos de antropomorfismo pagão, uma vez que a velha está identificada como a "vieille, sorcière, famme sage, vieille boîteuse". Para esse caso, porém, levanta-se uma outra hipótese: não se trataria de encurtamento da expressão arco da velha aliança, passando, assim, do antropomorfismo pagão para o antropomorfismo cristão? Nesse sentido, manifestou-se Ferreira (1991, p.22), afirmando:

A velha pode interpretar-se de duas maneiras. Segundo alguns autores, seria uma redução de Velha Aliança, em referência ao episódio bíblico da aliança estabelecida entre Deus e Noé depois do dilúvio e de que o arco-íris seria o sinal. É essa a explicação que foi dada, no século XVI, por Frei Heitor Pinto e que foi retomada no século XVIII por D. Raphael Bluteau [...]

Outra hipótese, defendida por José Leite de Vasconcelos e, em geral, pelos etnólogos, é que se trataria de uma "velha", uma espécie de bruxa que aparece tantas vezes ligada a fenômenos atmosféricos [...] (FERREIRA, 1991, p. 22).

São duas possibilidades de interpretação, mas faltam-nos elementos que permitam, categoricamente, colocar uma face a outra e indicar a verdadeira. Fica, ainda, uma questão para ser considerada: a alternância arco da velha / arcodo-velho. Tal alternância explica-se pela perda de motivação, decorrente da não mais relação direta com aliança, o que pode ter levado a reinterpretar-se o adjetivo como substantivo, alternando-se, assim, a posse entre o masculino e o feminino.

\subsection{Expressões para Prostituta}

Na Bahia e em Sergipe, para se referir a mulher que se vende para qualquer homem, registram-se três expressões que apresentam as seguintes 
estruturas: substantivo + substantivo (mulher-dama), substantivo + adjetivo (mulher-solteira) e verbo + substantivo (varre-rua).

A expressão mulher-dama está dicionarizada em Ferreira (2004), versão eletrônica, como um substantivo feminino, brasileirismo popular do nordeste, sinônimo de meretriz. Em relação à presença de empréstimos do francês no léxico rural brasileiro, no caso em questão, o item dame, Cardoso e Ferreira (2000) referem-se à nítida disseminação de formas francesas que, com o passar do tempo, perderam a sua vitalidade no falar urbano, remanescendo nos falares rurais, ilustrando, assim, momentos de distinta interferência cultural que deixaram as suas marcas na língua portuguesa.

A expressão mulher-solteira também está registrada em Ferreira (2004), versão eletrônica, como substantivo feminino, brasileirismo popular do nordeste, sinônimo de meretriz. Para a perfeita interpretação dessa denominação, necessário se faz entender o uso de "solteira" em certas áreas rurais brasileiras, como as de Bahia e Sergipe. Na cultura local, a mulher era criada seguindo uma lógica social: crescer, casar-se e constituir, assim, família, A mulher que ficava "solteira", isto é, não seguiu esse ritual, era olhada com certa desconfiança e sempre vista como uma transgressora, em potencial, das normas sociais, ou seja, capaz de ter amores fortuitos. Isso levou a que, nessas áreas, a denominação socialmente aceita e desprovida de estigma fosse "moça", para quem não se casou, versus "casada", para quem contraiu matrimônio, ficando a forma de langue "solteira" marcada negativamente e aplicada para recobrir o conceito "prostituta". Essa designação tem, pois, alto grau de motivação, e marca uma fase da sociedade rural do nordeste brasileiro, em que a mulher tinha dois caminhos: casar-se ou virar prostituta, ou seja, ser mulhersolteira.

A outra expressão selecionada, varre-rua, tem caráter extremamente depreciativo. Trata-se de uma designação com conotação pejorativa, com transparente alusão à pessoa que exerce a função de varrer a rua, ou seja, procede à limpeza das áreas sem selecionar o tipo de lixo, mas varrendo tudo que encontra pelo caminho. E essa é a ideia que passa à denominação: a mulher que fica com qualquer um, desde que se lhe pague.

\subsection{Expressões para Entrar na menopausa}

Entre as unidades fraseológicas documentadas nos atlas referentes a Bahia e Sergipe, encontram-se as formas verbais amarrar, quebrar, tirar e cair 
seguidas do substantivo facão, utilizadas com o sentido de "entrar na menopausa".

As expressões amarrar, quebrar, tirar, cair o facão se referem, metaforicamente, ao abandono de um instrumento de trabalho, isto é, o facão, e suscitam as seguintes considerações:

(i) O facão é um importante instrumento de trabalho nas áreas rurais, especialmente no trabalho agrícola. Como observa Cardoso (1998): "A simbologia do facão para o homem do campo é muito forte. Ao usá-lo preso à cintura, como geralmente o usa, o facão torna-se símbolo do trabalho, da produção, da força, da segurança e da capacidade de autodefesa." (p. 112).

(ii) A procriação é vista como uma importante função da mulher, com o mesmo valor do trabalho desenvolvido no campo. Ao entrar na menopausa, ela abandona essa função, isto é, "quebra", "amarra", "tira da cintura", "deixa cair" o facão, como o agricultor que não vai mais sair para o campo.

(iii) Fraseologia com o mesmo sentido, com utilização de outro elemento metafórico é "pendurar as chuteiras", de referência ao jogador que deixou de competir e, portanto, colocou de lado um dos objetos que utiliza na atividade.

Quanto ao registro nos dicionários, Ferreira (1999) documenta amarrar o facão, com o sentido de "chegar ao climatério", como brasileirismo popular da Bahia.

No Houaiss; Villar (2001), encontra-se a expressão passar o facão, classificada como "linguagem informal", no sentido de "dispensar alguém do emprego", o que vem corroborar a interpretação sugerida acima.

Deve-se ressaltar, ainda, como o faz Cardoso (1998) que "A naturalidade com que ocorre faz com que, na área, a expressão fulana amarrou o facão seja neutra e desprovida de qualquer conotação pejorativa, equivalendo exatamente a "entrar na menopausa".

\section{UMA PALAVRA DE CONCLUSÃO}

O corpus em que se baseia este estudo fornece uma amostra da riqueza fraseológica de que se revestem os falares regionais brasileiros. A interação com a realidade cultural da área em que se inserem as denominações mostra a explícita relação homem-meio.

O estudo de expressões do léxico rural de Bahia e Sergipe apresentado permite, a título de conclusão, as seguintes considerações: 
(i) As criações lexicais analisadas contemplam a pluriverbalização.

(ii) O falante atribui nomes criados sob diferentes motivações: função, como ilustram as expressões varre-rua, amarrar o facão e associações mentais/analogias, como no caso de sete-cores.

(iii) As unidades fraseológicas refletem a estabilidade no sentido atribuído por Tristá (1988) de relação tão estreita entre os elementos que os leva a perderem o significado primário para adquirirem um novo sentido.

\section{REFERENCIAS}

AGUILERA, Vanderci de Andrade. Atlas Lingüístico do Paraná. Curitiba: Imprensa Oficial do Estado, 1994. 2 v.

ALINEI, Mario. Arc-en-ciel. In:Atlas Linguarum Europae. Assen-Maastricht: Van Gorcum, I, 1983, Volume I-Commentaires.

AMARAL, Amadeu. O dialeto caipira. 2. ed. São Paulo: HUICITEC; Secretaria de Ciência e Tecnologia, 1976.

ARAGÃO, Maria do Socorro Silva de. A Parassinonímia em atlas linguísticos regionais brasileiros. In: Grosse, Sybylle; SCHÖNBERGER, Axel (orgs.) Ex oriente lux. Festschrift für Eberhard Gärtner zu seinem 60.Geburtstag. Farnkfurt am Main: Valentia, 2002. p. 5768.

ARAGÃO, Maria do Socorro Silva de; MENEZES, Cleuza Bezerra de. Atlas Lingüístico da Paraíba. Brasília: UFPB; CNPq, Coordenação Editorial, 1984.

BESSA, José Rogério Fontenele (coordenador). Atlas Linguístico do Estado do Ceará. Fortaleza: Edições UFC, 2010.

CARDOSO, Suzana Alice Marcelino. As "cores" do arco-íris no Brasil. In: AGRELO, Ana Isabel Boullón (ed.). Novi te ex nomine. Estudos filolóxicos ofrecidos ao prof. Dr. Dieter Kremer. A Coruña: Fundación Pedro Barrié de la Maza, 2004. p. 69-81.

CARDOSO, Suzana Alice Marcelino. Arco-íris, estrela cadente e Via Láctea: que traçados fazem do português do Brasil? Revista Portuguesa de Filologia, v. XXIV, Coimbra, 2002. p.77-99.

CARDOSO, Suzana Alice; FERREIRA, Carlota da Silveira. O léxico rural: glossário, comentários. Salvador: Universidade Federal da Bahia, 2000.

CARDOSO, Suzana Alice Marcelino; FERREIRA, Carlota. O arco-íris no Brasil: um estudo lingüístico-antropológico a partir dos atlas regionais. Revista do GELNE-Grupo de Estudos Lingüísticos do Nordeste, Fortaleza, n. 2, 1999. p. 21-24.

CARDOSO, Suzana Alice Marcelino. Inovação e conservadorismo no léxico rural brasileiro. In: XXI CONGRESSO INTERNAZIONALE DI LINGUISTICA E FILOLOGIA ROMANZA, 1995, Palermo. Atti... v. 5. Tubingen: Max Niemeyer, 1998. p. 109-119.

CRUZ, Maria Luíza de Carvalho. Atlas Lingüístico do Amazonas. Tese de 
Doutorado.Universidade Federal do Rio de Janeiro, 2004

FERREIRA, Aurélio Buarque de Holanda. Novo Aurélio Século XXI: o dicionário da língua portuguesa. $3^{\text {a }}$. ed., totalmente revista e ampliada. Rio de Janeiro: Nova Fronteira, 1999.

FERREIRA, Carlota; FREITAS, Judith; MOTA, Jacyra; ANDRADE, Nadja; CARDOSO, Suzana; ROLLEMBERG, Vera; ROSSI, Nelson. Atlas Lingüístico de Sergipe. Salvador: Universidade Federal da Bahia; Fundação Estadual de Cultura de Sergipe, 1987.

FERREIRA, Manuela Barros. Portugal no Atlas Linguarum Europae (ALE). In: GASPAR, Jorge et ali. Portugal e a Europa. Identidade e diversidade. Rio Tinto/Portugal: Edições Asa, 1991.

HOUAISS, Antônio: VILLAR, Mauro de Salles. Dicionário Houaiss da língua portuguesa. Rio de Janeiro: Objetiva. 2001

MARROQUIM, Mário. A língua do Nordeste. 3. ed. Curitiba: HD Livros, 1996.

NASCENTES, Antenor. O linguajar carioca. 2. ed. Rio de Janeiro: Organização Simões, 1953.

OLIVEIRA, Dercir Pedro (org.). Atlas Lingüístico de Mato Grosso do Sul. Campo Grande: Ed. UFMS, 2007.

RIBEIRO, José; ZÁGARI, Mário Roberto Lobuglio; PASSINI, José; GAIO,. Antônio Pereira. Esboço de um Atlas Lingüístico de Minas Gerais. Rio de Janeiro: Ministério da Educação e Cultura; Casa de Rui Barbosa; Universidade Federal de Juiz de Fora, 1977.

ROSSI, Nelson, FERREIRA, Carlota, ISENSEE Dinah. Atlas Prévio dos Falares Baianos. Rio de Janeiro, Ministério de Educação e Cultura - Instituto Nacional do Livro, 1963.

TRISTÁ, Antonia María. Fraseología y contexto. Havana: Editorial de Ciencias Sociales, 1988.

Nota do editor:

Artigo submetido para avaliação em: 08 de agosto de 2018.

Aprovado em sistema duplo cego em: 27 de setembro de 2018. 